\title{
Implementation and initial evaluation of a decision support platform for selecting production routes of biomass-derived chemicals
}

\author{
Marinella Tsakalova ${ }^{\mathrm{a}}$, Ta-Chen Lin ${ }^{\mathrm{b}}$, Aidong Yang ${ }^{\mathrm{b}}$, Antonis C. Kokossis ${ }^{\mathrm{a}}$ \\ ${ }^{a}$ School of Chemical Engineering, National Technical University of Athens, Greece \\ ${ }^{b}$ Faculty of Engineering and Physical Sciences, University of Surrey, UK
}

\begin{abstract}
A decision support platform is developed to evaluate and screen options for producing chemicals from biomass feedstock. The platform is based on the modelling of the socalled compartmental processing blocks (CPBs) and their connections. It includes a simulation tool and a synthesis/optimisation tool, both based on a central database which holds process and economic information about individual CPBs. The synthesis/ optimisation tool performs screening over multiple production routes by means of modelling and optimisation of superstructures that represent possible feedstock, routes, and products in a given case of assessment. The current implementation uses Excel for the database and the simulation tool, while the synthesis/optimisation tool is based on GAMS. A case study on green ethylene production is reported to illustrate the application of the platform.
\end{abstract}

Keywords: biomass processing, modelling, optimization, synthesis

\section{Introduction}

In light of limited and uncertain supply of conventional, fossil feedstock as well as challenges of climate change, biomass as alternative feedstock has received increasing attention in connection with the objective of sustaining the chemical industry in a long run. In comparison with the knowledge, technology, and supply chains already established in conventional petrochemical industry, producing chemicals from biomass at scale poses a large number of options from which the "best" ones are yet to be chosen. More specifically, one needs to screen over several economical and environmental objectives optimizing the selection of feedstocks and products, as well as the selection of processing routes and technologies. A support system with capabilities to facilitate high-level decisions would be highly useful to individual companies and public organizations, which is a task the CAPE community has expertise to address (Dimian, 2007; Klatt and Marquardt, 2009; Kokossis and Yang, 2010).

Among other efforts in this area (see Kokossis and Yang, 2010 for a review), the Accessing Biomass for Chemicals (ABC) project supported by the Department of Environment, Food and Rural Area (DEFRA) in UK has been developing a systematic approach to screen biomass processing options and to identify the optimal production routes. The central idea is to build modelling and optimisation capacities into a systems platform to support decision making (Kokossis et al., 2010). In this paper, the approach is first summarised in Section 2. Section 3 describes the design and implementation of the decision support platform. A case study chosen for evaluating the platform is subsequently reported in Section 4. 


\section{The modelling and optimisation approach}

As previously presented in Kokossis et al. (2010), a multi-step production route based on biomass feedstock can be viewed as a system composed of a number of connected Compartmental Processing Blocks or CPBs. One CPB may represent a process section (e.g. gasification) or even a complete process plant (e.g. a bioethanol plant). Consequently, the evaluation of one production route or the screening over multiple routes will be based on the modelling of individual CPBs as well as their connections. Figure 1 illustrates how this is done by starting with the modelling of the (bio) chemical process embedded in the CPB. It can be seen that the result of process modelling will drive the estimation of energy consumption, greenhouse gas (GHG) emission as well as the variable operating cost. Note that fixed costs (including capital cost and fixed operating cost) need to be estimated with additional information other than the result of process modelling.

Capital costs have been estimated using Taylor's method (Taylor, 1997). Depending on the purpose of analysis, the calculation of energy consumption and GHG emission can be performed with two different system boundaries, namely "cradle to factory outlet" and "factory inlet to outlet". Energy implication and GHG footprint associated with the use of the products are not considered in this project.

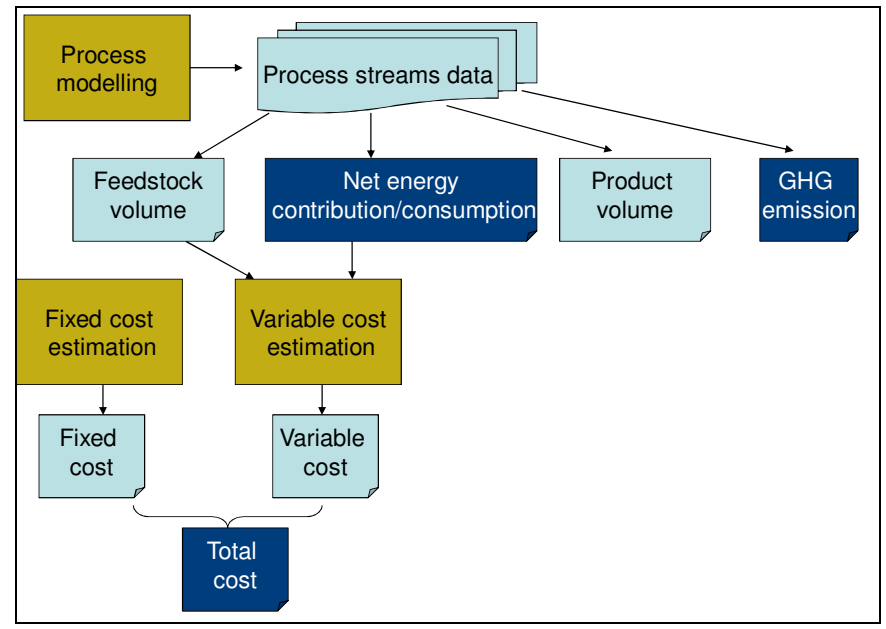

Figure 1. The modelling approach

On the basis of the above modelling capacities, both simulation of individual production routes and simultaneous screening of multiple routes via optimisation are possible. As for the latter aspect, a process synthesis approach has been adopted to not only perform screening but also identify possible integration between different routes. This is based on setting up a superstructure that represents all the options for feedstock, processing steps, as well as products that should be considered in a given case. In this context, a $\mathrm{CPB}$ is viewed as a basic building block of the superstructure. Figure 2 provides an illustrative example for a superstructure defined for producing ethylene and propylene glycol from biomass or biomass derived feedstock. Each rectangle box represents a CPB. For a given objective function, the optimisation of such a superstructure should provide suggestions on the optimal route or the optimal combination of multiple routes. 


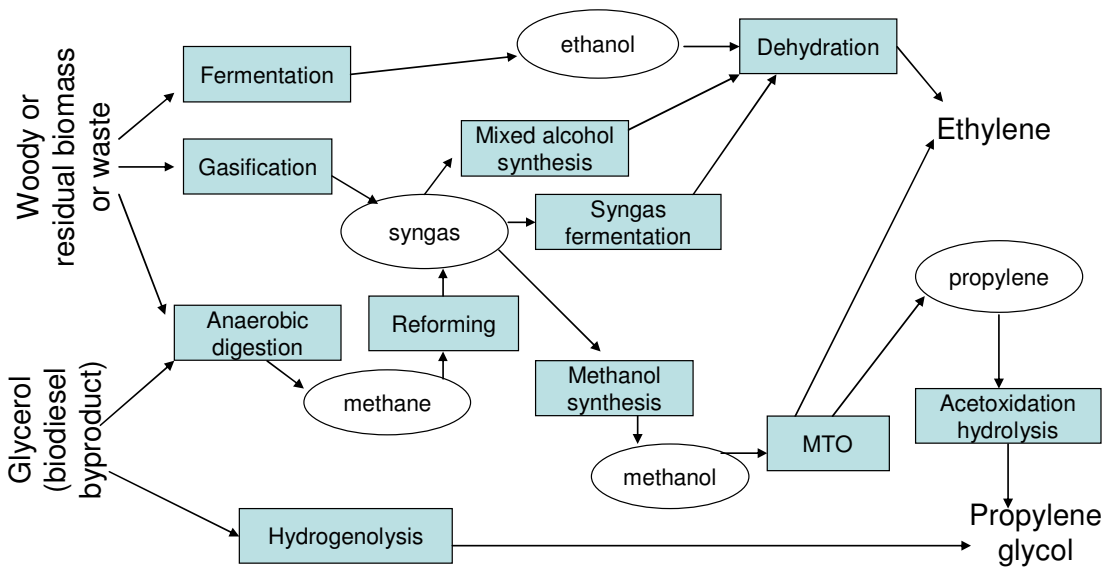

Figure 2. An illustrative example of superstructures

\section{Design and implementation of the decision support platform}

As shown in Figure 3, the systems platform is designed to have three main components, namely the platform database, the simulation tool, and the synthesis/optimisation tool.

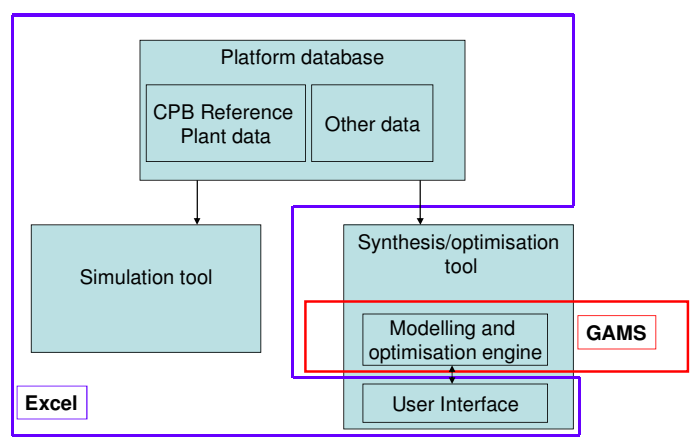

Figure 3. Design and implementation of the systems platform

The database holds data of each CPB specified at a reference scale of operation. These data include material and energy flows, service requirements with respect to cooling water, waste water treatment, as well as waste disposal. Furthermore, capital and fixed operating cost figures associated with this CPB are also included. The list of CPB's to be included into the database within this project is shown in Table 1. Apart from the $\mathrm{CPB}$ data, the database further accommodates information such as the prices of chemicals and utilities, which may be shared by different CPB's.

The simulation tool implements functions requiring for evaluating individual production routes. It makes use of the information of the database, allows a user to describe a production route in terms of the order of several CPB's and the scale of production, and performs evaluation of the economics, energy consumption, and GHG emission of each part of the route as well as the entire route as a whole.

The synthesis/optimisation tool is responsible to screen over multiple routes represented by means of a superstructure. Linked to the database, it hosts the superstructure model (as a combination of CPB models and connectivity representation) and offers optimisation solvers for solving the superstructure model.

In terms of software implementation, the shared database and the simulation tool are implemented in Excel. GAMS has been chosen as the modelling environment for the 
synthesis/optimisation tool. Furthermore, a user interface is being implemented in Excel to support users to set up superstructures.

Table 1. List of CPB's included in the ABC project

\begin{tabular}{|l|l|}
\hline N1 & Biomass Fermentation to Ethanol - Grain wastes \\
\hline N2 & ABE fermentation \\
\hline N3 & Syngas fermentation to ethanol \\
\hline N4 & Biomass AD for Biogas (CH4) \\
\hline N5 & Glycerol to Biogas (CH4) by AD \\
\hline N6 & Plant oil to biodiesel \& Glycerol \\
\hline N7 & Biomass Gasification - Indirect \\
\hline N8 & Biomass Gasification - Direct \\
\hline N9 & Mixed Alcohol synthesis from Syngas \\
\hline C10 & Propylene to Propylene Glycol \\
\hline C11 & Glycerol to Propylene Glycol by chemical reaction \\
\hline C12 & Biogas (CH4) reforming to Syngas \\
\hline C13 & Propylene to acetone \\
\hline C14 & Propylene to Butanol \\
\hline C15 & Methanol synthesis from Syngas \\
\hline C16 & Syngas to NH3 \\
\hline C17 & Methanol to olefins \\
\hline C18 & Ethanol dehydration to Ethylene \\
\hline
\end{tabular}

\section{Case study: green ethylene}

A subset of the production routes shown in Figure 2 is taken here to illustrate the application of the decision support platform. This includes four different routes for producing ethylene from biomass. Applying the simulation tool and assuming 4000kt/yr of biomass feedstock is processed, different rankings of these routes are shown in Table 2. The economic performance is evaluated by means of annualised net profit; economic value of both the main product (ethylene) and the by-products has been taken into account. Energy consumptions cover the sum of electricity, steam, and combustion fuel, each of which is converted to the equivalent quantity of primary fuel in terms of lower heating value. GHG emission focuses on $\mathrm{CO}_{2}$ only and is calculated referring to a boundary same as that of the production system. All these three performance indicators were evaluated at a basis of per tonne ethylene produced.

Using the same four routes to compose a superstructure, two simple, economicsoriented optimisation problems were solved by the synthesis/optimisation tool as an initial evaluation of the tool. In the first problem, the optimiser was to choose either corn stover (feeding one route) or wood chips (feeding three routes) as the feedstock, each available at a quantity up to $4000 \mathrm{kt} /$ year. The result showed the route with corn stover as the feedstock (i.e. Route 1 as in Table 2) was chosen, consistent with the simulation results. In the second problem, corn stover was set to be available with a quantity up to $1000 \mathrm{kt} /$ year, while wood chips up to $3000 \mathrm{kt} /$ year. The optimisation subsequently suggested using all the corn stover for Route 1, producing ethanol to join that produced by Route 2 (defined in Table 2) which takes all the wood chips available. For the simulation results shown in Table 2 this combination appears to be reasonable. 
Table 2. Ranking of production routes based on simulation analysis

\begin{tabular}{|c|l|c|c|c|}
\hline \multirow{2}{*}{$\begin{array}{c}\text { Route } \\
\text { No. }\end{array}$} & \multicolumn{1}{|c|}{ Route } & Economics & $\begin{array}{c}\text { Energy } \\
\text { consumption }\end{array}$ & $\begin{array}{c}\text { GHG } \\
\text { emission }\end{array}$ \\
\hline 1 & $\begin{array}{l}\text { Corn stover ->fermentation-> } \\
\text { ethanol->dehydration->ethylene }\end{array}$ & {$[1]$} & {$[1]$} & {$[2]$} \\
\hline 2 & $\begin{array}{l}\text { Wood chips->gasification-> } \\
\text { syngas->mixed alcohol synthesis-> } \\
\text { ethanol (and mixed higher alcohol) } \\
->\text { dehydration->ethylene }\end{array}$ & {$[2]$} & {$[3]$} & {$[3]$} \\
\hline 3 & $\begin{array}{l}\text { Woodchips->gasification-> } \\
\text { syngas->syngas fermentation-> } \\
\text { ethanol->dehydration->ethylene }\end{array}$ & {$[3]$} & {$[2]$} & {$[1]$} \\
\hline 4 & $\begin{array}{l}\text { Wood chips->gasification-> } \\
\text { syngas->methanol synthesis> } \\
\text { methanol->MTO->thylene } \\
\text { (and propylene etc.) }\end{array}$ & {$[4]$} & {$[4]$} & {$[4]$} \\
\hline
\end{tabular}

\section{Conclusions}

Introducing renewable biomass into the manufacturing of energy and chemical products poses great challenges as well as opportunities to process systems engineering. This requires extensions of established methods and tools to address new problems in this area. Reporting ongoing work in the $\mathrm{ABC}$ project, this paper presents a decision support platform for evaluating and screening possible production routes for biomass-derived chemicals. Based on the modelling of individual processing blocks, the platform offers simulation and optimisation capacities by means of tools implemented in Excel and GAMS, as illustrated by a simple case study on green ethylene. This platform is now being further developed and evaluated with more sophisticated cases within the ABC project.

\section{Acknowledgement}

Financial support from Defra (UK) via Project LK0855 and contributions from the project consortium are acknowledged.

\section{References}

Dimian, A. C. (2007). Renewable raw materials: chance and challenge for computer-aided process engineering. Computer Aided Chemical Engineering, 24, 309-318.

Klatt, K.-U., Marquardt, W. (2009). Perspectives for process systems engineering. Personal views from academia and industry. Comput. Chem.Eng. 33, 536-550.

Kokossis, A., Yang, A. (2010). On the use of systems technologies and a systematic approach for the synthesis and the design of future biorefineries. Comput. Chem. Eng. 34, 1397-1405.

Kokossis, A., Yang, A., Tsakalova, M., Lin., T.-C. (2010). A systems platform for the optimal synthesis of biomass based manufacturing systems. Computer Aided Chemical Engineering, 28, 1105-1110.

Taylor, J. H. (1977). The process step scoring method for making quick capital estimates. Engineering and Process Economics 2, 259. 